\title{
Evaluation of the stability of biochemical phenotypes of Escherichia coli upon subculturing and storage
}

\author{
M. KaTOULI, ${ }^{1 *}$ I. KÜHN ${ }^{1,2}$ and R. MöLlBY ${ }^{1}$ \\ ${ }^{1}$ Department of Bacteriology, Karolinska Institute, S-10401 Stockholm, Sweden \\ ${ }^{2}$ Department of Bacteriology, National Bacteriological Laboratory, S-105 21 Stockholm, Sweden
}

(Received 22 February 1990; revised 10 May 1990; accepted 5 June 1990)

\begin{abstract}
Stability of the biotypic characters of 72 enteropathogenic Escherichia coli (EPEC) and 21 faecal $E$. coli strains was evaluated after storage and after subculturing using a computerized biochemical fingerprinting method. Sixteen (22\%) EPEC strains and nine (43\%) faecal strains exhibited changes in their biochemical reactions after subculturing. In contrast, strains stored at $-70{ }^{\circ} \mathrm{C}$ and $4{ }^{\circ} \mathrm{C}$ did not show any measurable changes. Of 23 biochemical markers tested, eight were subject to changes in at least one of these strains. Change in lactulose fermentation was most frequent, occurring in $17(18 \%)$ strains. A decrease or loss of activity in the fermentation of 5-ketogluconate, arbutin and methyl $\beta$-D-glucoside in six strains $(6 \%)$, and an increase in the ability to ferment sucrose, raffinose, melibiose and D-arabinose in 20 strains $(22 \%)$ were observed. Mean similarity of the strains, when compared pairwise before and after subculturing, was slightly affected by these changes, but the overall biochemical phenotypes of the strains remained constant.
\end{abstract}

\section{Introduction}

Biochemical reactions have been conventionally used for identification of bacteria to the species level. The usefulness of these markers to subdivide strains below the species level, however, is greatly dependent on the variability of these characters within the species and the distribution of these variations (Lockhart \& Liston, 1970). Extensive studies of the biochemical reactions of bacteria have been done to introduce biochemical typing systems in epidemiological studies of bacteria (Barr \& Hogg, 1979; Krishnan et al., 1987; Crichton \& Old, 1982). To achieve maximum discrimination, biotyping together with serotyping (Simoons-Smit et al., 1985; van der Waaij et al., 1976), serotyping and phage typing (Rennie et al., 1978), serotyping and fimbriation analysis (Brauner et al., 1987), serotyping and outer-membrane protein (OMP) analysis (Stenderup \& Ørskov, 1983; Achtman et al., 1983) or sero/OMP/electrophoretic analysis of alloenzymes (Ochman \& Selander, 1984) have been suggested for the study of epidemiologically important bacterial clones. The value of biotyping in combination with the other bacterial properties used in

\footnotetext{
Abbreviations: EPEC, enteropathogenic Escherichia coli; F, deepfrozen, $\mathrm{N}$, non-subcultured and $\mathrm{S}$, subcultured strains; OMP, outermembrane protein.
}

these studies, however, relies to a great extent on the reproducibility and discriminative power of the biochemical reactions used. Kühn (1985) developed a biochemical typing method based on the measurement of the kinetics of several biochemical reactions of bacterial strains grown in liquid media in microtitre plates. This method yields a biochemical fingerprint of each strain which consists of several quantitative data which can be used to establish similarity levels among the tested strains using a personal computer. With this method Kühn et al. (1985) studied clones of enterotoxigenic $E$. coli (ETEC) strains which had been isolated from Swedish piglets over a period of 20 years and also ETEC strains isolated from humans in different geographical areas (Kühn \& Möllby, 1986). They found stable biochemical phenotypes among certain ETEC serogroups, most of them also carrying the relevant virulence factors.

Many studies on the prevalence of virulence factors among $E$. coli strains isolated from different outbreaks or sporadic cases throughout the world have shown that subculturing and/or storage may have a drastic effect on the loss or expression of these factors (Evans et al., 1977; Levine et al., 1983). However, few investigations have assessed the stability of biochemical reactions following such environmental pressures.

The aim of the present study was to measure the 
stability of the biochemical markers of $E$. coli strains after storage and subculturing and to compare the biochemical phenotypes of these strains before and after such treatments.

\section{Methods}

E. coli strains. A total of 72 EPEC strains were tested in this study. They belonged to 11 different serogroups, namely O26 (8 strains), O44 (8 strains), O55 (7 strains), O86 (1 strain), O111 (8 strains), O114 (10 strains), O119 (6 strains), O125 (9 strains), O126 (5 strains), O127 (6 strains) and 0128 (4 strains). Of these, 68 strains were obtained from the collection of the National Bacteriological Laboratory (NBL), Stockholm, Sweden, and four strains were obtained from K. Wachsmuth, Center for Disease Control, Atlanta, USA. All EPEC strains had been isolated from diarrhoeal cases and had been stored for a period of up to 10 years. Twenty-one faecal $E$. coli strains isolated from healthy adults in Sweden, and stored for 4 years, were provided by A. Brauner, SMCL, Stockholm, Sweden. $O$ antigens of EPEC strains were determined using poly- and monovalent antisera (NBL) and confirmed by tube agglutination. $\mathrm{K}$ and $\mathrm{H}$ antigens were not determined.

Storage and subculturing. Strains were kept at $-70{ }^{\circ} \mathrm{C}$ in screwcapped tubes, containing nutrient broth and $50 \%(\mathrm{v} / \mathrm{v})$ glycerol. This set of the strains was called 'deep-frozen' $(F)$. Replicates of these strains on Tryptic Soy Agar (TSA; Difco), kept at $4{ }^{\circ} \mathrm{C}$, were designated the 'non-subcultured' (N) set. From these, successive subcultures were made daily on TSA for $21 \mathrm{~d}$, followed by incubation at $37^{\circ} \mathrm{C}$ overnight. This set was named 'sub-cultured' (S). Each set was plated on MacConkey agar (Difco) and checked for purity before biochemical testing, and a single colony was spread on nutrient agar (Difco) and incubated at $37^{\circ} \mathrm{C}$ for $24 \mathrm{~h}$.

Biochemical fingerprinting. Preparation of prefabricated microplates (PhP system; BioSys Inova, Stockholm, Sweden) and selection of the appropriate reagents for fingerprinting $E$. coli strains have been described previously (Kühn \& Heden, 1976; Kühn, 1985). Table 1 shows a set of 24 reagents that have been specially selected for characterization of $E$. coli strains. One of these reagents, cellobiose, gives negative results for all $E$. coli strains, and was included to check for contamination by other bacteria.

A loopful of the cultures of the organisms on nutrient agar was suspended in $8 \mathrm{ml}$ sterile $0.2 \%$ (w/v) proteose peptone (Difco) solution, containing $0.01 \%(\mathrm{w} / \mathrm{v})$ bromothymol blue as indicator. Aliquots $(150 \mu \mathrm{l})$ of the suspension were transferred to the 24 wells in a microtitre plate with the aid of a multi-channel pipette, giving a final reagent

Table 1. Reagents used for the biochemical fingerprinting of E. coli strains

\begin{tabular}{lll}
\hline \hline & & \\
D-Xylose & Deoxyribose & Ornithine \\
Maltose & Sucrose & 5-Ketogluconate \\
Lactose & Raffinose & Melibionate \\
Sorbitol & Sorbose & Arbutin \\
Rhamnose & Tagatose & D-Arabinose \\
L-Fucose & D-Arabitol & Methyl $\beta$-D-glucoside \\
Glycerol & Adonitol & Lactulose \\
Melibiose & Dulcitol & Cellobiose* \\
\hline \hline
\end{tabular}

* Used to check for the presence of contaminating species. concentration of $3.75 \mathrm{mg} \mathrm{ml}^{-1}$ in each well. Using 24 reagents, four strains can be tested in each plate. To allow proper rehydration of the reagents, the inoculated plates were kept in a refrigerator overnight before incubation.

Reading and calculation. The plates were incubated at $37^{\circ} \mathrm{C}$ and the $A_{620}$ of each reaction read after $4,7,24$ and $48 \mathrm{~h}$ using a microplate reader (Titertek Multiskan, Flow Laboratories). The $A_{620}$ values were automatically transferred to a personal computer (Victor-V286C) and multiplied by 10 , yielding scores ranging from 0 to 30 for each reaction. Low values represent acidic reactions (yellow), and high values, alkaline reactions (deep blue). The mean value for all four readings of each reaction was calculated, yielding 24 different values scored from 0 to 30 for each strain (the biochemical fingerprint).

Similarities between strains, when compared pairwise, were measured by calculating the correlation coefficient $(r)$ according to the formula:

$$
r=\frac{\sum_{i=1}^{24}\left(X_{i}-\bar{X}\right)\left(Y_{i}-\bar{Y}\right)}{\sqrt{\sum_{i=1}^{24}\left(X_{\mathrm{i}}-\bar{X}\right)^{2} \sum_{i=1}^{24}\left(Y_{i}-\bar{Y}\right)^{2}}}
$$

where $X_{i}$ is the value of the $i$ th reaction for the strain $\mathrm{X}, Y_{i}$ is the value of the $i$ th reaction for strain $\mathrm{Y}$, and $\bar{X}$ and $\bar{Y}$ are the mean values of all 24 scores for strains $X$ and $Y$, respectively. A correlation coefficient close to 1 for a pair of $E$. coli strains means that the two strains have similar biochemical fingerprints, whereas low correlation coefficient values mean different test results and indicate that the strains are less related. Interassay variation for each test was measured by testing 50 strains in duplicate. Values outside the mean \pm 2 SD for a test were taken to indicate changes in that particular test. Strains showing changes based on this criterion were retested to rule out the effect of random errors. Clustering of the isolates was done according to the single linkage clustering method (Sneath \& Sokal, 1973).

\section{Results}

Of $93 E$. coli strains tested in this study, 25 strains $(27 \%)$ exhibited changes in one or more of their biochemical reactions after subculturing when compared to the original, $\mathrm{N}$ strains. Of these, 16 strains $(22 \%)$ belonged to EPEC serogroups and nine strains $(43 \%)$ were control strains $(P=0 \cdot 06)$. Among the EPEC strains those belonging to serogroups $\mathrm{O} 26, \mathrm{O} 44$ and $\mathrm{O} 127$ did not show any changes in their biochemical reactions after subculturing. The mean correlation coefficient of the strains, when compared pairwise before and after subculturing, was affected by these changes (Table 2). To determine whether these changes were due to subculturing rather than to storage, each strain was assayed pairwise without subculturing ( $\mathrm{N}$ vs $\mathrm{N}$ strains), without and with subculturing ( $\mathrm{N}$ vs $\mathrm{S}$ strains), and finally, without subculturing and after deep freezing ( $N$ vs $\mathrm{F}$ strains). The results showed a clear drift towards lower similarity coefficients when $S$ strains were compared to the other groups (Fig. 1). Further analysis showed that eight out of 23 biochemical test results (cellobiose was not included), had changed in at least one of these strains. Change in 


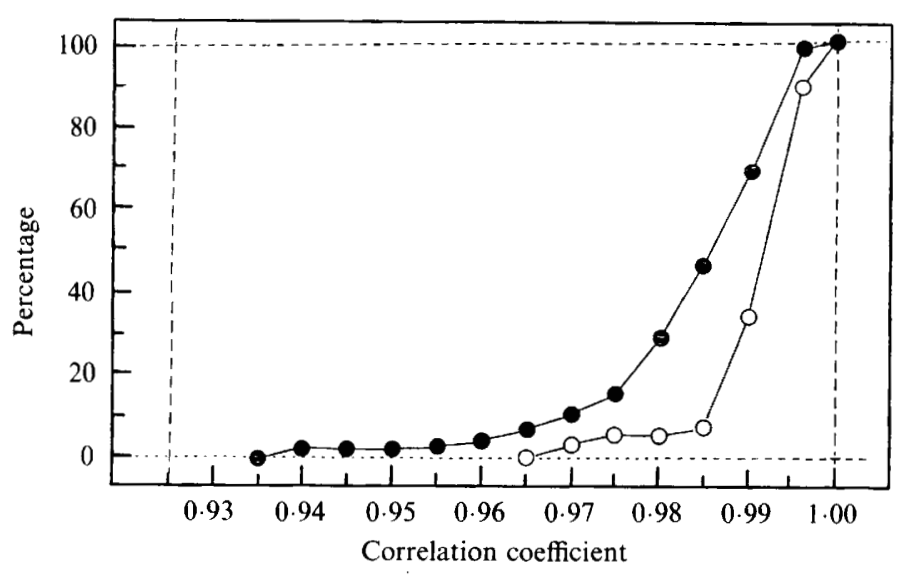

Fig. 1. Cumulative relative frequencies of the correlation coefficients (r) obtained from pairwise comparison of $93 E$. coli strains. Correlation coefficients were grouped into different class intervals to show differences between the distribution of $r$, between paired strains: $O$, before subculturing, $\mathbf{N}$ vs $\mathbf{N}$ strains, i.e. interassay reproducibility; before and after subculturing, $\mathrm{N}$ vs $\mathrm{S}$ strains.

lactulose fermentation was most frequent, occurring in 17 strains, followed by raffinose in five strains, melibionate and arbutin in four strains each, and finally 5ketogluconate, methyl $\beta$-D-glucoside and D-arabinose in only one strain each. Of 25 strains, 16 showed changes in only one of the biochemical reactions, eight showed changes in two reactions and one showed changes in three reactions (Table 3 ).

Two distinct patterns of changes in these bacteria were observed. A decrease or loss of activity with fermentation of 5-ketogluconate, arbutin and methyl $\beta$-D-gluco-

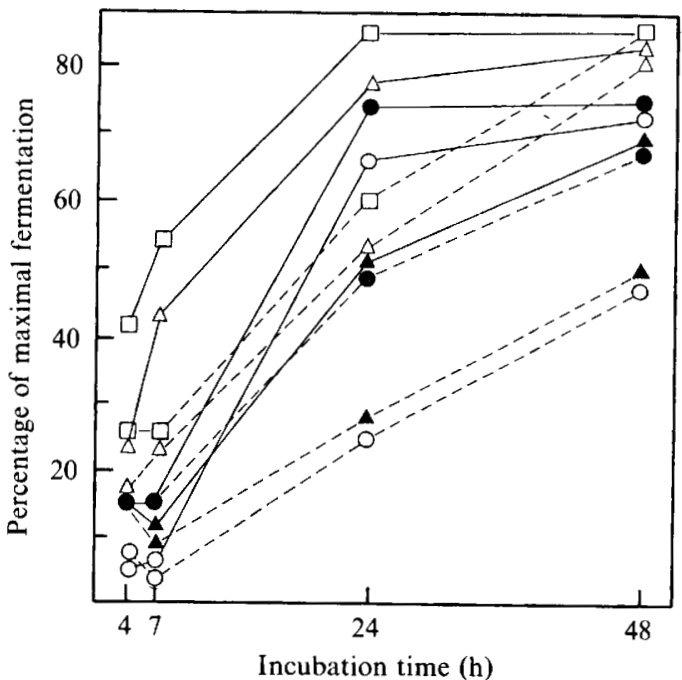

Fig. 2. Pattern of the increased fermentative ability of $20 \mathrm{E}$. coli strains showing measurable changes in their biochemical reactions upon subculturing. Results are means expressed as a percentage of maximal fermentation, before subculturing (-- ) and after subculturing $(-)$. $\square$, Lactulose (17 strains); $\triangle$, raffinose (5 strains); $\boldsymbol{O}$, sucrose (2 strains); $\boldsymbol{\Delta}, \mathrm{D}$-arabinose (1 strain); $\bigcirc$, melibionate (4 strains).

side (negative values), and an increase or gain of activity with raffinose, sucrose, melibionate, D-arabinose and lactulose (positive values) (see Table 3 ). Twenty $S$ strains demonstrated an increase in both speed and/or level of fermentation of five different substrates. Utilization of lactulose and sucrose was almost completed within the first $24 \mathrm{~h}$ among these strains, whereas with $\mathrm{N}$ strains this was achieved after $48 \mathrm{~h}$ (Fig. 2). Fermentation of

Table 2. Comparison of the correlation coefficients of E. coli strains showing differences in their biochemical reactions before and after subculturing

\begin{tabular}{|c|c|c|c|}
\hline \multirow{2}{*}{$\begin{array}{l}E . \text { coli } \\
\text { strains } \\
\text { (sero } \\
\text { group) }\end{array}$} & \multirow{2}{*}{$\begin{array}{c}\text { No. of strains } \\
\text { tested (no. } \\
\text { showing changes } \\
\text { after } \\
\text { subculturing) }\end{array}$} & \multicolumn{2}{|c|}{$\begin{array}{l}\text { Mean correlation coefficients } \pm \text { SD of } \\
\text { the strains tested in duplicate }\end{array}$} \\
\hline & & $\begin{array}{c}\text { Before } \\
\text { subculturing }\end{array}$ & $\begin{array}{l}\text { Before and after } \\
\text { subculturing }\end{array}$ \\
\hline \multicolumn{4}{|l|}{ EPEC strains } \\
\hline 026 & 8 & $0.995 \pm 0.001$ & $0.985 \pm 0.005$ \\
\hline O44 & 8 & $0.994 \pm 0.001$ & $0.988 \pm 0.004$ \\
\hline 055 & $7(1)$ & $0.992 \pm 0.002$ & $0.984 \pm 0.008$ \\
\hline 086 & 1 & 0.992 & 0.995 \\
\hline 0111 & $8(2)$ & $0.988 \pm 0.007$ & $0.988 \pm 0.005$ \\
\hline 0114 & $10(5)$ & $0.986 \pm 0.013$ & $0.983 \pm 0.009$ \\
\hline 0119 & $6(3)$ & $0.989 \pm 0.003$ & $0.970 \pm 0.015$ \\
\hline 0125 & $9(3)$ & $0.991 \pm 0.004$ & $0.978 \pm 0.014$ \\
\hline 0126 & $5(1)$ & $0.993 \pm 0.003$ & $0.987 \pm 0.008$ \\
\hline 0127 & 6 & $0.993 \pm 0.001$ & $0.991 \pm 0.003$ \\
\hline 0128 & $4(1)$ & $0.990 \pm 0.002$ & $0.975 \pm 0.008$ \\
\hline Subtotal & $72(16)$ & $0.991 \pm 0.005$ & $0.983 \pm 0.01$ \\
\hline Faecal strains & $21(9)$ & $0.991 \pm 0.002$ & $0.986 \pm 0.006$ \\
\hline Total & $93(25)$ & $0.991 \pm 0.002$ & $0.984 \pm 0.01$ \\
\hline
\end{tabular}




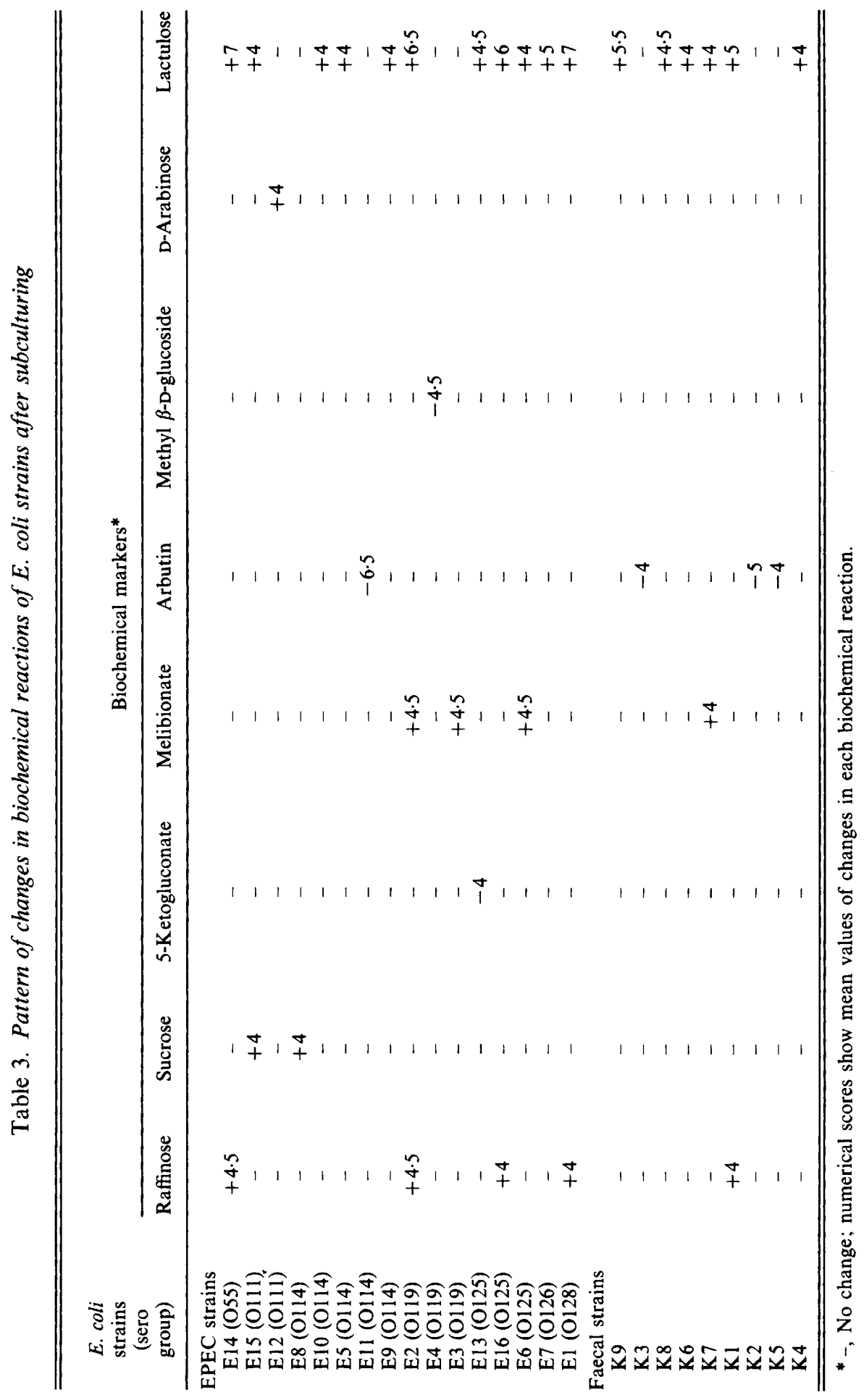


D-arabinose and melibionate on the other hand, was not only faster by $\mathrm{S}$ strains during the first $24 \mathrm{~h}$, but was also more complete than by $\mathrm{N}$ strains after $48 \mathrm{~h}$. Six strains showed an overall decrease in their ability to utilize arbutin (4 strains), methyl $\beta$-D-glucoside (1 strain) and 5ketogluconate (1 strain) during $48 \mathrm{~h}$ of the experiment (Fig. 3). Loss of ability to utilize these compounds was generally not accompanied by an increase in the utilization of other substrates among these strains.

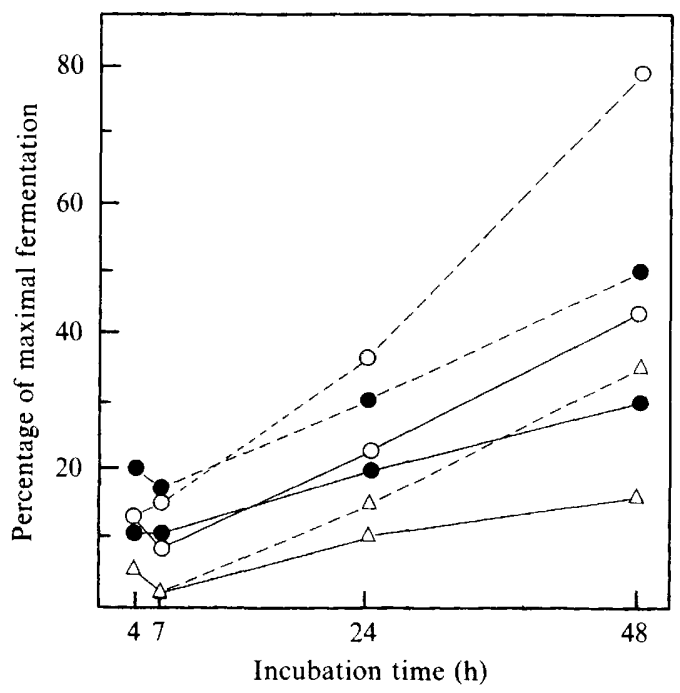

Fig. 3. Pattern of the decreased fermentative ability of six E. coli strains, showing measurable changes in their biochemical reactions, upon subculturing. Results are means expressed as a percentage of maximal fermentation before subculturing (- - ) and after subculturing ( - ). $O$, Arbutin (4 strains);, , methyl $\beta$-D-glucoside ( 1 strain); $\triangle, 5$-ketogluconate (1 strain).
To evaluate the effect of these changes in biochemical reactions on the reproducibility of phenotyping of strains before and after subculturing and/or storage, a dendrogram was constructed for 22 strains with recognizable changes (Fig. 4). It was shown that although there was a drift towards a lower similarity when $\mathrm{S}$ strains were compared to $\mathrm{N}$ and $\mathrm{F}$ strains, the $\mathrm{S}$ strains were still very closely related to their origins and only one strain fell into another phenotype (strain E2).

\section{Discussion}

Extensive studies of the biochemical reactions of $E$. coli strains isolated from different sources have been made in the past (Crichton \& Old, 1979; Gargan et al., 1982; Godbout-DeLasalle \& Higgins, 1986). To subdivide these strains into more distinct types for epidemiological purposes most authors have employed either conventional test methods (Bettelheim \& Taylor, 1969; Crichton \& Old, 1979) or commercially available biochemical test systems (Davies, 1977; Cicmanec \& Evans, 1980). In practice, most of the strains to be tested for such purposes would inevitably go through different periods of storage and probably a series of subcultures. Our results on the effect of such environmental pressures on the stability of the biochemical reactions of $E$. coli strains showed that subculturing might have some effect on the ability of these strains to express some, if not all, of their biochemical markers. With storage, however, this effect depends to a certain extent, on the conditions in which the strains are stored.

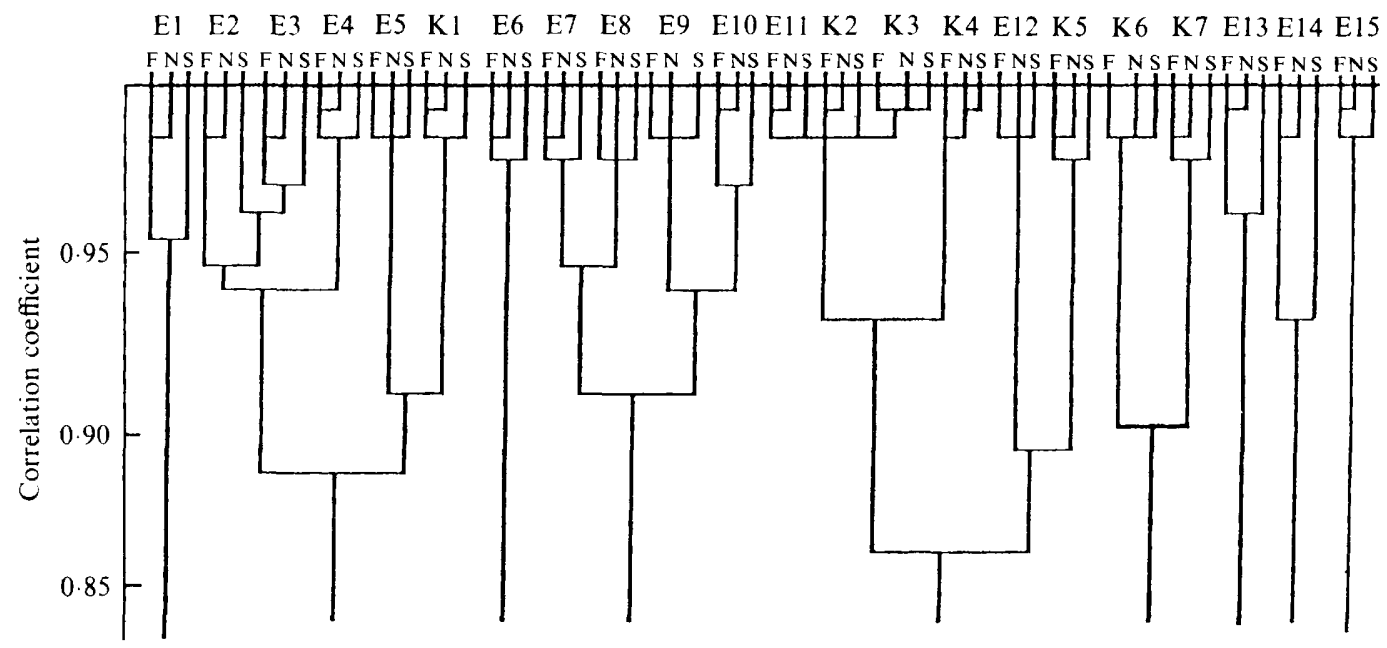

Fig. 4. Dendrogram of 22 strains with measurable changes in their biochemical profile. For each strain, deep-frozen (F), nonsubcultured $(\mathrm{N})$ and subcultured $(\mathrm{S})$ variants were analysed. 
Using a computerized biochemical fingerprinting method, we compared E. coli strains stored at $-70^{\circ} \mathrm{C}$, to those continuously subcultured or stored at $4{ }^{\circ} \mathrm{C}$ for $21 \mathrm{~d}$. As expected, the $\mathrm{F}$ strains were more similar to the $\mathrm{N}$ strains than to the S strains. Crichton \& Old (1979) tested many E. coli strains from different culture collections, and also from urinary tract infections, for their biotype stability after many months, and even years. They found that many colonies of E. coli strains stored on Dorset's egg slants exhibited the same biotype as that originally identified when the strains were isolated from a fresh specimen. Like many other investigators, these workers also used an absolute 'positive' or 'negative' value system to measure the biochemical reaction after a definite incubation time (between 24 and $72 \mathrm{~h}$ ). Therefore, a prompt early reaction within a shorter period than $24 \mathrm{~h}$ was not detected. This could explain the slight differences between our results and those obtained by these workers. Furthermore, the biochemical reactions used in the PhP system have been specifically selected from a large number of reactions so as to have a suitable variability with time (Kühn, 1985).

Differences in biochemical reactions were observed when $\mathrm{S}$ strains were compared to $\mathrm{N}$ strains. About a quarter of the strains were subject to measurable changes in up to three of the biochemical tests. Eight of the 23 biochemical reactions (cellobiose not included) used in this study showed changed after subculturing, among which two distinct patterns were dominant. With sucrose, raffinose and lactulose, there was a rapid increase in the rate of fermentation within the first $24 \mathrm{~h}$ of incubation, reaching approximately the same level as those of $\mathrm{N}$ strains after $48 \mathrm{~h}$. With melibionate and arabinose, however, this change occurred in both the speed of reaction and also the level of fermentation. The reason for this more rapid metabolism of these substances among $\mathrm{S}$ strains could not be explained simply. The regulatory genes responsible for the synthesis of the necessary enzymes may have been induced during the subculturing process, or S strains may have evolved a more efficient uptake system to assimilate the compounds, or a combination of both processes may have occurred.

Another difference in the metabolic reaction of the $\mathrm{S}$ strains was associated with a decrease in the final level and, to a certain extent, with the speed of the reactions. This was observed with arbutin, methyl $\beta$-D-glucoside, and 5-ketogluconate. In total, seven $E$. coli strains showed changes in the fermentation of these compounds. The final level of utilization of these compounds among $S$ strains was always much less than that of $\mathbf{N}$ strains. This loss of fermentation ability was not accompanied by any increase in fermentation of other substrates among these bacteria.
One of the factors which might have influenced the results is the growth medium. Composition of the media and also their physical states have been shown to have a great effect on the morphology (Iwaya et al., 1978), ultrastructure (Lorian et al., 1982) and growth rate (Brown et al., 1988) of bacteria, and to produce differences in the biochemical constitution of bacteria and their metabolites (Lorian, 1989). Local accumulation of metabolites in the surrounding environment of the bacteria, when they are grown on solid media, has been postulated to be a factor in repression or activation of the genes responsible for the enzymic action of these bacteria (Lorian, 1989). Therefore, it is possible that the $E$. coli strains which showed changes in their biochemical reactions will give a different pattern when they are subcultured on different and/or liquid media.

In comparison with control strains, EPEC strains seemed to be more stable in their metabolic characters after subculturing. Only $22 \%$ of the EPEC strains tested in this study showed changes in their biochemical reactions. The equivalent value for faecal $E$. coli strains was almost twice as high ( $43 \%$ ), which is not surprising, as the stability of some other phenotypic characters within clonal populations of EPEC strains has also been reported by other investigators (Ørskov \& Ørskov, 1983).

Another interesting feature of this study was that some of the $\mathrm{S}$ bacteria, without any obvious changes in a single test, had a lower overall similarity when they were compared with $\mathrm{N}$ strains. The changes in individual biochemical markers within these bacteria were too small to be spotted, but they were spread over 23 reactions, resulting in slightly different biochemical fingerprint for these strains.

We retested the $\mathrm{S}$ strains with measurable changes after another 3 months of storage at $4{ }^{\circ} \mathrm{C}$ and compared them to the $\mathrm{N}$ strains (data not shown). The results indicated that most of the changes, including those of lactulose fermentation, were stable.

In view of the fact that more than $18 \%$ of the strains tested in this study showed changes in their lactulose fermentation, we suggest that this test should not be included in biotyping systems for $E$. coli strains, if the system is used for epidemiological studies of isolates from diverse sources. However, if the system is used to detect very small changes in $E$. coli strains, lactulose fermentation is a very good marker.

Kühn (1985) used a minimum correlation coefficient of 0.975 to define identity between $E$. coli isolates. In the present study, the duplicate assays yielded a mean correlation coefficient of 0.991 (Table 2), giving a reproducibility level of the biochemical fingerprinting system of 0.985 (mean correlation coefficient $-2 \mathrm{sD}$ ). However, when the $\mathbf{S}$ strains were compared to the corresponding $\mathrm{N}$ strains, $13(14 \%)$ comparisons yielded 
lower similarity than $\mathbf{0 . 9 7 5}$, and if the lactose test was excluded, $7(8 \%)$ comparisons fell below this limit.

The biochemical similarity between different isolates with a common ancestor depends on two factors: firstly, the reproducibility of the assay, and secondly, the extent of the changes the isolates have gone through since their divergence from their common ancestor. The first factor may be measured easily, whereas the second factor cannot be predicted. It is, therefore, important in epidemiological studies, when the bacteria have been isolated from diverse sources, not only to investigate whether they are identical or not, but also to give a measure on how similar the isolates are to each other. This information may easily be shown in a dendrogram such as the one in Fig. 4. On the other hand, if the aim of the study is to detect identical strains from a recent outbreak, as in most nosocomial studies, the same identity level which has been used by Kühn (1985) and Kühn \& Möllby (1986) might be applicable.

The need for, and the role and importance of biotyping of bacterial isolates has been presented previously (Balows \& Isenberg, 1978; Farmer, 1978). Both conventional biotyping methods and commercial biotyping kits have been employed by many workers. It has been shown that several variables may influence the reproducibility of the biochemical tests. These include inoculum size, time of reading, the interpretation of the results by different workers, temperature of incubation and many others. While certain tests like aesculin hydrolysis are inoculum dependent (Miskin \& Edberg, 1978), less effect has been observed with carbohydrates (Crichton \& Old, 1979). Most of the test reagents employed in our study were carbohydrates. We also obtained the same results when the strains were retested in plates of different batches. Thus, the computerized biochemical fingerprinting method is not only an easy technique for detecting identity between strains, but also useful for detecting possible changes of biochemical reactions of bacteria due to subculturing, storage and other environmental factors.

In conclusion, our results demonstrate that upon repeated subculturing, $E$. coli strains change their biochemical activity profiles slightly. These biochemical reactions seem to be less stable among normal faecal $E$. coli than among a collection of EPEC strains. It is recommended that the most readily altered biochemical activity, lactulose fermentation, is not included in routine biotyping procedures.

We want to thank Ms Birgitta Karlsson and Ms Gunnel Sigstam for skilful technical assistance. This study was financially supported by the Swedish Board for Agricultural and Forestry Research, grants numbers 0564/89 L 139:1 and 0777/89 D 326:1, and from the Karolinska Institute funds.

\section{References}

Achtman, M., Mercer, A., Kusecek, B., Pohl, A., Heuzenroeder, M., Aaonson, W., Sutton, A. \& Silver, R. P. (1983). Six widespread bacterial clones among Escherichia coli $\mathrm{K} 1$ isolates. Infection and Immunity 39, 315-335.

Balows, A. \& ISENBERG, H. D. (1978). Biotyping in the Clinical Microbiology Laboratory. Springfield, Illinois: Charles C. Thomas.

BARR, J. G. \& HoGG, G. M. (1979). Biotypes of Klebsiella pneumoniae (sensu lato) and Enterobacter aerogenes characterized by differential substrate metabolism: application of the technique. Journal of Clinical Pathology 32, 935-943.

BetTelheim, K. A. \& TAYloR, J. (1969). A study of Escherichia coli isolated from chronic urinary infection. Journal of Medical Microbiology 2, 225-236.

Brauner, A., Boeufgras, J. M., Jacobson, S. H., Kaijser, B., Källenius, G., Svenson, S. B. \& Wretlind, B. (1987). The use of biochemical markers, serotype and fimbriation in the detection of Escherichia coli clones. Journal of General Microbiology 133, 28252834.

Brown, M. R. W., Allison, D. G. \& Gilbert, P. (1988). Resistance of bacterial biofilm to antibiotics: a growth rate related effect? Journal of Antimicrobial Chemotherapy 22, 777-783.

Cicmanec, F. J. \& Evans, A. T. (1980). Classification of urinary tract infections by biotype identification of the pathogens. Journal of Urology 124, 68-69.

Crichton, P. B. \& OLD, D. C. (1979). Biotyping of Escherichia coli. Journal of Medical Microbiology 12, 473-486.

Crichton, P. B. \& OLD, D. C. (1982). A biotyping scheme for the subspecific discrimination of Escherichia coli. Journal of Medical Microbiology 15, 233-241.

DAVIES, B. I. (1977). Biochemical typing of urinary Escherichia coli strains by means of the API $20 \mathrm{E}$ enterobacteriaceae system. Journal of Medical Microbiology 10, 293-298.

Evans, D. J., Evans, D. G., DuPont, H. C., Ørskov, F. \& Ørskov, I. (1977). Pattern of loss of enterotoxigenicity by Escherichia col isolated from adults with diarrhea. Suggestive evidence for an interrelationship with serotypes. Infection and Immunity 17, 105-111.

FARMER, J. J. (1978). Biotyping of nonfermentative, gram-negative bacteria. In Biotyping in the Clinical Microbiology Laboratory. pp. 2632. Edited by A. Balows \& H. D. Isenberg. Springfield, Illinois: Charles C. Thomas.

Gargan, R., Brumfitt, W. \& Hamilton-Miller, J. M. T. (1982). A concise biotyping system for differentiating strains of Escherichia coli. Journal of Clinical Pathology 35, 1366-1369.

Godbout-DeLasalle, F. \& Higgins, R. (1986). Biotyping of clinical isolates of Escherichia coli of animal origin, using the Analytab API 20E system. Canadian Journal of Veterinary Research 50, 418-421.

IWAYA, M., Goldman, R., TipPer, D. J., Finegold, B. \& STrominger, J. L. (1978). Morphology of an Escherichia coli mutant with a temperature-dependent round cell shape. Journal of Bacteriology 136, $1143-1158$.

Krishnan, C., Fitzgerald, V. A., Dakin, S. J. \& Behme, R. J. (1987). Laboratory investigation of outbreak of hemorrhagic colitis caused by Escherichia coli $0157:$ H7. Journal of Clinical Microbiology 25, 1043-1047.

KüHN, I. (1985). Biochemical fingerprinting of Escherichia coli. A simple method for epidemiological investigations. Journal of Microbiological Methods 3, 159-170.

KüHN, I. \& HEDEN, C. G. (1976). From biotyping to metabolic fingerprinting. In Rapid Methods and Automation in Microbiology, pp. 173-177. Edited by H. H. Johnston \& S. W. B. Newson. Oxford: Learned Information Ltd.

KÜHN, I. \& MölLBY, R. (1986). Phenotypic variation among enterotoxigenic O-groups of Escherichia coli from human populations. Medical Microbiology and Immunology 175, 15-26.

KüHN, I. Franklin, A., SöDerlind, O. \& Möllby, R. (1985). Phenotypical variations among enterotoxigenic Escherichia coli from Swedish piglets with diarrhoea during 1964-1984. Medical Microbiology and Immunology 174, 119-130. 
LeVine, M. M., Ristanio, P., SaCK, R. B., Kaper, J., ØRSKov, F. \& ØRSKOV, I. (1983). Colonization factor antigens I and II and type 1 somatic pili in enterotoxigenic Escherichia coli, relation to enterotoxin type. Infection and Immunity 39, 889-897.

LockharT, W. R. \& Liston, J. (1970). Methods for Numerical Taxonomy. Bethesda, Maryland: American Society for Microbiology.

LORIAN, V. (1989). In vitro simulation of in vivo conditions: physical state of the culture medium. Journal of Clinical Microbiology 27, 2403-2406

LORIAN, V., ATKINSON, B., WALUSChKa, A. \& KIM, Y. (1982). Ultrastructure, in vitro and in vivo, of staphylococci exposed to antibiotics. Current Microbiology 7, 301-304.

Miskin, A. \& EDBERG, S. C. (1978). Esculin hydrolysis reaction by Escherichia coli. Journal of Clinical Microbiology 7, 251-254.

OCHMAN, H. \& SELANDER, R. K. (1984). Evidence for clonal population structure in Escherichia coli. Proceedings of the National Academy of Sciences of the United States of America 81, 198-201.

ØRSKOV, F. \& ØRSKOV, I. (1983). Summary of a workshop on the clone concept in the epidemiology, taxonomy, and evaluation of the Enterobacteriaceae and other bacteria. Journal of Infectious Diseases 148, 346-357.

RenNie, R. P., Nord, C. E., SJöBerg, L. \& DunCaN, I. B. R. (1978). Comparison of bacteriophage typing, serotyping and biotyping as aids in epidemiological surveillance of Klebsiella infections. Journal of Clinical Microbiology 8, 638-642.

Simoons-Smit, A. M., VerweiJ-VAn VaGHT, A. M. J. J., Kanis, I. Y. R. \& MACLAREN, D. N. (1985). Biochemical and serological investigations on clinical isolates of Klebsiella. Journal of Hygiene 95, 265276.

Sneath, P. H. A. \& SoKal, R. R. (1973). Numerical Taxonomy. San Francisco: W. H. Freeman.

STENDERUP, J. \& ØRSKOV, F. (1983). The clonal nature of enteropathogenic Escherichia coli strains. Journal of Infectious Diseases 148, 10191024.

Van der WaAis, D., Speltie, T. M., Guinee, P. A. M. \& Agterberg, C. (1975). Serotyping and biotyping of 160 Escherichia coli strains: comparative study. Journal of Clinical Microbiology 1, 237-238. 